\title{
Technical note: Use of a digital and an optical Brix refractometer to estimate total solids in milk replacer solutions for calves
}

\author{
H. K. Floren, W. M. Sischo, C. Crudo, and D. A. Moore ${ }^{1}$ \\ Department of Veterinary Clinical Sciences, Washington State University, Pullman 99164
}

\begin{abstract}
The Brix refractometer is used on dairy farms and calf ranches for colostrum quality (estimation of $\mathrm{IgG}$ concentration), estimation of serum IgG concentration in neonatal calves, and nonsalable milk evaluation of total solids for calf nutrition. Another potential use is to estimate the total solids concentrations of milk replacer mixes as an aid in monitoring feeding consistency. The purpose of this study was to evaluate the use of Brix refractometers to estimate total solids in milk replacer solutions and evaluate different replacer mixes for osmolality. Five different milk replacer powders $(2$ milk replacers with $28 \%$ crude protein and $25 \%$ fat and 3 with $22 \%$ crude protein and $20 \%$ fat) were mixed to achieve total solids concentrations from approximately 5.5 to $18 \%$, for a total of 90 different solutions. Readings from both digital and optical Brix refractometers were compared with total solids. The 2 types of refractometers' readings correlated well with one another. The digital and optical Brix readings were highly correlated with the total solids percentage. A value of 1.08 to 1.47 would need to be added to the Brix reading to estimate the total solids in the milk replacer mixes with the optical and digital refractometers, respectively. Osmolality was correlated with total solids percentage of the mixes, but the relationship was different depending on the type of milk replacer. The Brix refractometer can be beneficial in estimating total solids concentration in milk replacer mixes to help monitor milk replacer feeding consistency.
\end{abstract}

Key words: dairy calf, milk replacer, refractometer

\section{Technical Note}

The management of calves has an effect on future herd performance and herd economics (Davis Rincker et al., 2011; Khan et al., 2011; Soberon et al., 2012). Milk replacer feeding is commonly used because of vari-

\footnotetext{
Received December 28, 2015.

Accepted May 29, 2016.

${ }^{1}$ Corresponding author: damoore@vetmed.wsu.edu
}

ous benefits including cost, biosecurity, and consistency when compared with nonsalable milk. Of heifer raising operations surveyed by the USDA in $2011,86 \%$ used some milk replacer and $68 \%$ fed only milk replacer when rearing calves (USDA, 2012). Although feeding milk replacers is common, debate continues about best practices for feeding them (Kertz and Loften, 2013).

One difficulty with creating protocols for milk replacer feeding is that formulations have changed greatly since they were first introduced (Kertz and Loften, 2013). This means that research done on early milk replacers may no longer be relevant, although management decisions may still be based on those results. For example, an older study showed that calves fed higher amounts or concentrations of milk replacer were more likely to have diarrhea (Jenny et al., 1982), which led to some current practices for amounts and concentrations to be fed. Recent research has not found any relationship between increased solids in newer milk replacers and diarrhea (Bach et al., 2013).

Feeding consistency is important, especially in young animals. Studies have shown that even when fed greater nutrient levels compared with a control group, calves fed variable amounts of milk replacer did poorly under stress conditions (Quigley et al., 2006). Consistency of feeding a liquid diet supported better rates of gain in preweaned calves (Hill et al., 2009). When milk replacer was fed at an equal weekly intake but variable daily intake, calves had at a lower rate of gain than calves fed a consistent daily amount of milk replacer. Inconsistency in milk replacer mixing regardless of mixing instructions is possible and was demonstrated by Gelsinger and Heinrichs (2014), with dairy science students asked to mix according to label directions with the same measuring equipment. The final TS in their milk replacer mixes ranged from 10 to 15\%. Improving consistency of feeding would help minimize the potential for digestive upset (Drackley, 2008); inconsistency in waste milk feeding is also possible (Hill et al., 2009). A calf ranch feeding nonsalable milk from many different farms had variably low TS in the incoming waste milk (some less than $8 \%$ TS) when estimated with a Brix refractometer (Moore et al., 2009). 
On many dairy farms, preweaned calves are fed about $2 \mathrm{~L}$ twice a day at a level of solids 12.5 to $13 \%$ (Davis and Drackley, 1998; USDA, 2012). During cold, winter months, many farmers will concentrate their milk replacer mixes to provide more energy without changing the total volume fed. However, increasing the concentration of milk replacer might increase the osmolality of the fluid being fed, which can have various effects on calves (Smith and Berchtold, 2014). Some milk replacers may already have higher osmolalities compared with cow milk (Constable et al., 2005). One consequence of an osmolality above a recommended level is the association with a slower rate of abomasal emptying (Nouri and Constable, 2006). As the abomasal emptying rate slows, the risk of abomasal bloat increases because the presence of easily fermentable carbohydrates in the milk replacer and the slow emptying rate allow for excessive gas production and bloat (Marshall, 2009). The slower emptying rate caused by high osmolality may also maintain a higher $\mathrm{pH}$ in the abomasum (Constable et al., 2005), which could allow microbes that would normally be killed in the acidic environment to survive and pass into the intestine with the potential to cause diarrhea (Foster and Smith, 2009).

In addition to abomasal effects, high osmolality may also affect absorption in the small intestine. The effective osmolality at the tips of intestinal villi is approximately $600 \mathrm{mOsm} / \mathrm{kg}$ (Jodal and Lundgren, 1986). As intestinal contents are generally around $300 \mathrm{mOsm} / \mathrm{kg}$, an osmotic gradient exists for water absorption into the villi. When milk replacers or other fluids are fed at over $600 \mathrm{mOsm} / \mathrm{kg}$, the gradient is no longer as effective and absorption is inhibited, which could lead to an osmotic diarrhea. Osmotic diarrhea and dehydration was consistently induced in 2- to 7-d-old dairy calves with $600 \mathrm{mOsm} / \mathrm{L}$ of oral solution (Walker et al., 1998). Diarrhea and death due to salt toxicity as a result of high TS feeding (18.9-20.8\% TS) and high salinity farm water was reported (Ollivett and McGuirk, 2013). Whereas the stigma is that feeding more concentrated milk replacer can cause scours, it is likely that those effects are caused not by increased nutrients but by the increased osmolality of the fluid. This suggests that feeding concentrations may be as important to calf health as total nutrients offered, and care should be taken to not concentrate replacers to a point where they might be harmful.

Anecdotally, some farms have been using a Brix refractometer to measure TS in milk replacer mixes, although no evidence has been found to support that it estimates TS the same as with milk. Because the Brix refractometer has been shown useful to measure colostrum quality (Bielmann et al., 2010) and serum immu- noglobulins (Deelen et al., 2014), many farms already have this tool and its use for milk replacer evaluation is logical. The objectives of the current study were to establish relationships between Brix refractometer readings, osmolality, and TS in milk replacers to help dairies quantitatively measure consistency in mixing and feeding milk replacer.

Five samples of different milk replacer powders were collected from farms in the Pacific Northwest (Table 1). The milk replacer samples were placed in Whirl-Pak bags (Nasco, Fort Atkinson, WI) and frozen until analyzed. Two of the milk replacers contained $28 \%$ crude protein and $25 \%$ fat, whereas the other 3 contained $22 \% \mathrm{CP}$ and $20 \%$ fat. Dry matter content was measured for each of the milk replacers using a 1,000-W microwave oven (Emerson MW8115SS, Emerson Radio Corp., Parsippany, NJ) and a scale accurate to 0.001 g (Mettler-Toledo model PB303-S, Mettler-Toledo International Inc., Greifensee, Switzerland). Before using the scale, it was calibrated 3 times with a 1 -g standard weight to ensure it was reading consistently and accurately. An initial powder weight of approximately $1 \mathrm{~g}$ was measured and the sample was heated in the microwave for $2.5 \mathrm{~min}$ at $70 \%$ power, at which point the sample was reweighed. The sample was then heated at $70 \%$ power and weighed at 1-min intervals until the weight remained constant (4-6 min total). The final weight was recorded and divided by the initial weight to calculate the DM content of the sample. Each of the 5 milk replacers was tested in triplicate to obtain an average DM content to be used in future calculations.

To establish the relationship between Brix readings, osmolality, and TS, a wide range of concentrations of milk replacer were mixed. Because milk replacer on farm is generally mixed at rates of $0.45,0.57$, and 0.68 $\mathrm{kg}$ of powder per $3.78 \mathrm{~L}$ of water, samples were mixed at these rates as well as at lesser and greater concentrations for concentrations of $0.06,0.09,0.12,0.15,0.18$, and $0.22 \mathrm{~kg} / \mathrm{L}$ to provide for a wide range of values, above and below what is normally mixed, for a regression analysis. When preparing mixed samples, powder was measured in weigh boats on a scale accurate to 0.1 g (Ohaus Navigator N1D110, Ohaus Corporation, Parsippany, NJ) and transferred to 100-mL glass vials. Water was then added using a 10-mL pipette (Easypet 3, Eppendorf, Hamburg, Germany). A stirring rod was placed in each vial and the samples put on a heating/ stir plate (Cimarec 3, Barnstead/Thermolyne Corp., Dubuque, IA) set on low heat and a low stir rate. The samples were heated and stirred until all powder was dissolved. Lids were kept on the vials during heating to prevent evaporation. Once samples were mixed, three $500-\mu \mathrm{L}$ aliquots were taken from each using a 200- to 
Table 1. Guaranteed analysis (on a DM basis) and first 4 listed ingredients for 5 different milk replacer powders based on labels

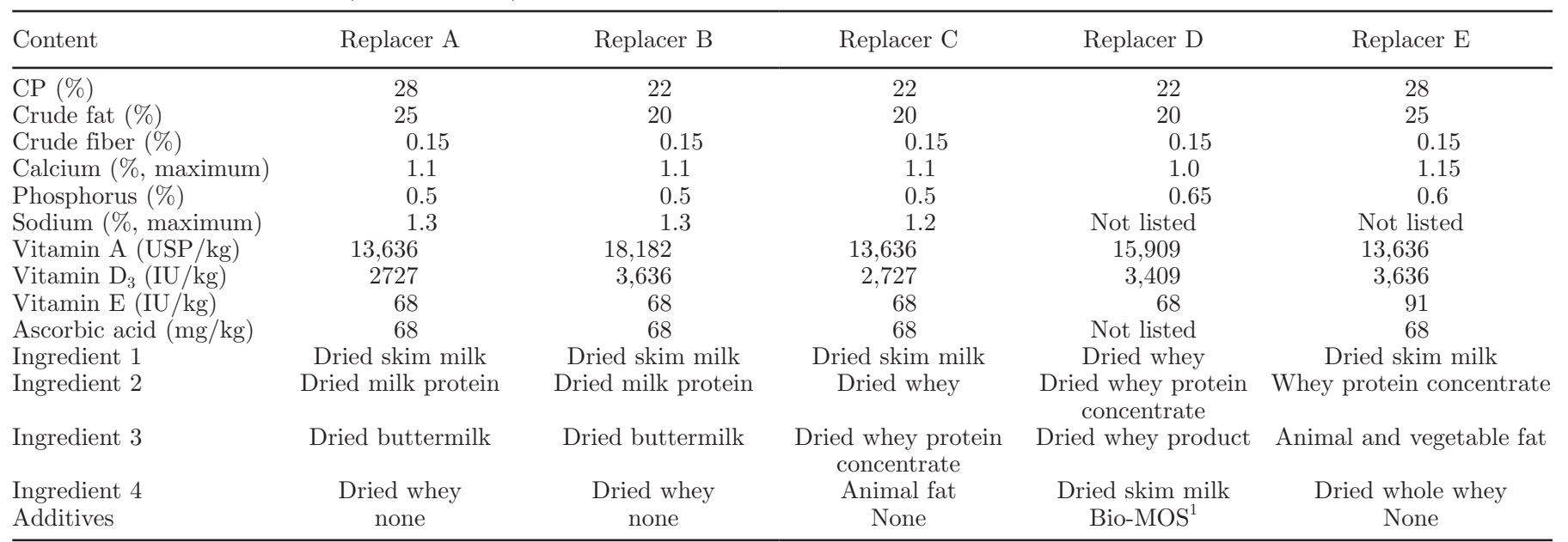

${ }^{1}$ Mannan oligosaccharide (Alltech Inc., Nicholasville, KY).

1,000- $\mu \mathrm{L}$ pipette (Finnpipette 4500, Labsystems, Waltham, MA) and placed in test tubes.

Actual TS for each sample were calculated using the DM determined for each specific replacer and the known mixing amounts. A digital refractometer (Pam Abbe model PA203X, MISCO Refractometer, Solon, $\mathrm{OH}$ ) was compared with an optical Brix refractometer (Reichert Brix 35HP, Reichert Inc., Depew, NY) using the same milk replacer mixes and concentrations. The data were analyzed using the GLM procedure in SAS (PROC GLM, release 9.3, SAS Institute Inc., Cary, $\mathrm{NC}$ ) with the Brix reading as the independent variable and TS percentage as the dependent variable. The calculated solids were plotted against Brix readings for each refractometer (Figure 1). Using the digital refractometer, we noted a linear relationship with the actual solids percentage $[\mathrm{Y}=0.96$ ( $\mathrm{SE}=0.02$; Brix reading) $+1.47(\mathrm{SE}=0.26)]$. About $95 \%$ of the variation in $\mathrm{TS}$ percentage could be explained by the Brix reading $(P$ $<0.001$ ). Using the optical refractometer, we found a linear relationship with the actual TS percentage $[\mathrm{Y}=$ $0.96(\mathrm{SE}=0.02$; Brix reading $)+1.08(\mathrm{SE}=0.29)]$. About $94 \%$ of the variation in solids percentage could be explained by the optical Brix reading $(P<0.001)$. A significant linear relationship was observed between the readings provided by the digital and the optical refractometers $\left[\right.$ digital $=1.01$ (optical) $-0.42 ; \mathrm{R}^{2}=$ 0.997; $P<0.001$.

To evaluate the effects of milk replacer concentration on osmolality, an osmometer (Advanced Model 3320 Micro-Osmometer, Advanced Instruments Inc., Norwood, MA) was standardized with Clinitrol 290 reference solution (Advanced Instruments Inc.) to within 4 points of the $290-\mathrm{mOsm} / \mathrm{kg}$ standard, similar to the osmolality of milk (Büttel et al., 2008). Once the osmometer was standardized, osmolality readings were taken on each of the milk replacer mix samples, in triplicate.

Osmolality in the sample mixes ranged from 121 to $664 \mathrm{mOsm} / \mathrm{kg}$ for the milk replacer mixes within a range of 5.45 to $17.85 \%$ TS. Two of the milk replacers, when mixed at the greater (over 16\% TS) concentrations had levels of osmolality above the suggested level of $600 \mathrm{mOsm} / \mathrm{kg}$ (Constable et al., 2005). We found a linear relationship between the osmolality of a milk replacer mix and the percent TS in that solution, but the relationship differed depending upon the specific milk replacer powder $(P<0.01$; Figure 2$)$. Milk replacer $\mathrm{C}$ (22\% CP, $20 \%$ fat milk replacer) had the highest slope $[\mathrm{Y}=44.8$ (TS) - 129.1] and milk replacer E (28\% CP, $25 \%$ fat milk replacer) had the lowest slope $[\mathrm{Y}=28.3$ (TS) - 50.1; Figure 2]

In conclusion, there is a high correlation between Brix readings and actual TS of the mixed milk replacers evaluated. Although the digital refractometer gave slightly different estimates compared with the optical refractometer, the 2 refractometer readings were highly correlated across a wide range of concentrations, from very low $(0.06 \mathrm{~kg} / \mathrm{L})$ to very high $(0.22)$. This suggests that a Brix refractometer is useful for estimating the TS levels of milk replacer mixes. If using the digital refractometer to estimate the TS percentage, a value of 1.5 would be added to the Brix reading (a Brix reading of 12 indicates a TS of 13.5\%). If using the optical refractometer, a value of 1.1 would be added to the Brix reading (a Brix reading of 12 indicates TS of about $13.1 \%$ ). These estimations are different compared with previous work with whole milk, which showed that the 
Brix refractometer read 2 points lower than actual TS (so a Brix reading of 11 indicated TS of $13 \%$; Moore et al., 2009). The reason for this difference should be explored, although it may be assumed that different compositions of the fluids could lead to the discrepancy.

The osmolality of each type of milk replacer was linearly related to total solids. However, we found dif- ferences among the different replacers with regards to the relationship between TS percent and osmolality; the reason for this is unknown. Although osmolality cannot be measured on farm, osmolality might become a concern when farms mix more concentrated replacer, as may be done in winter, or when additives are placed in the milk or milk replacer. Osmolality can only be

a)

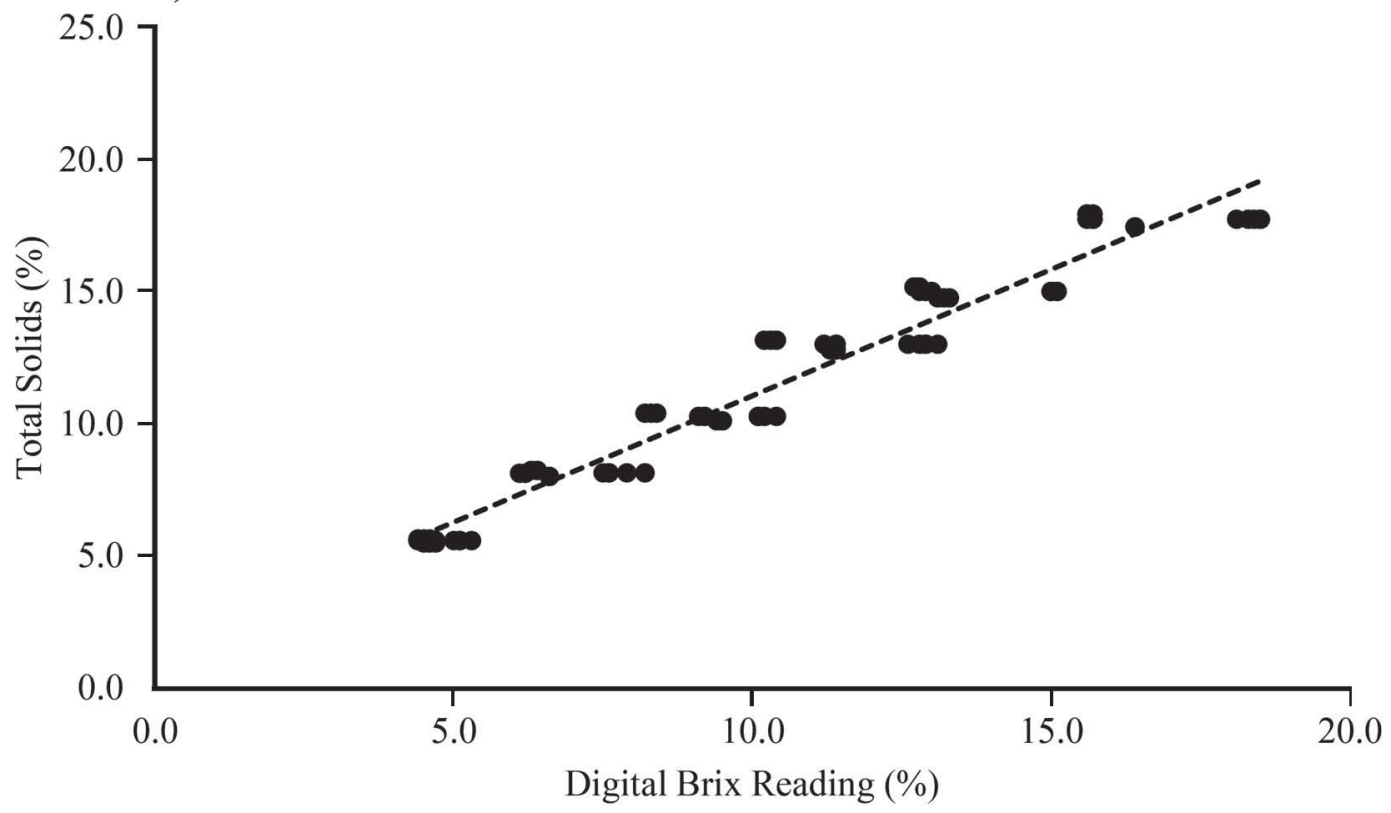

b)

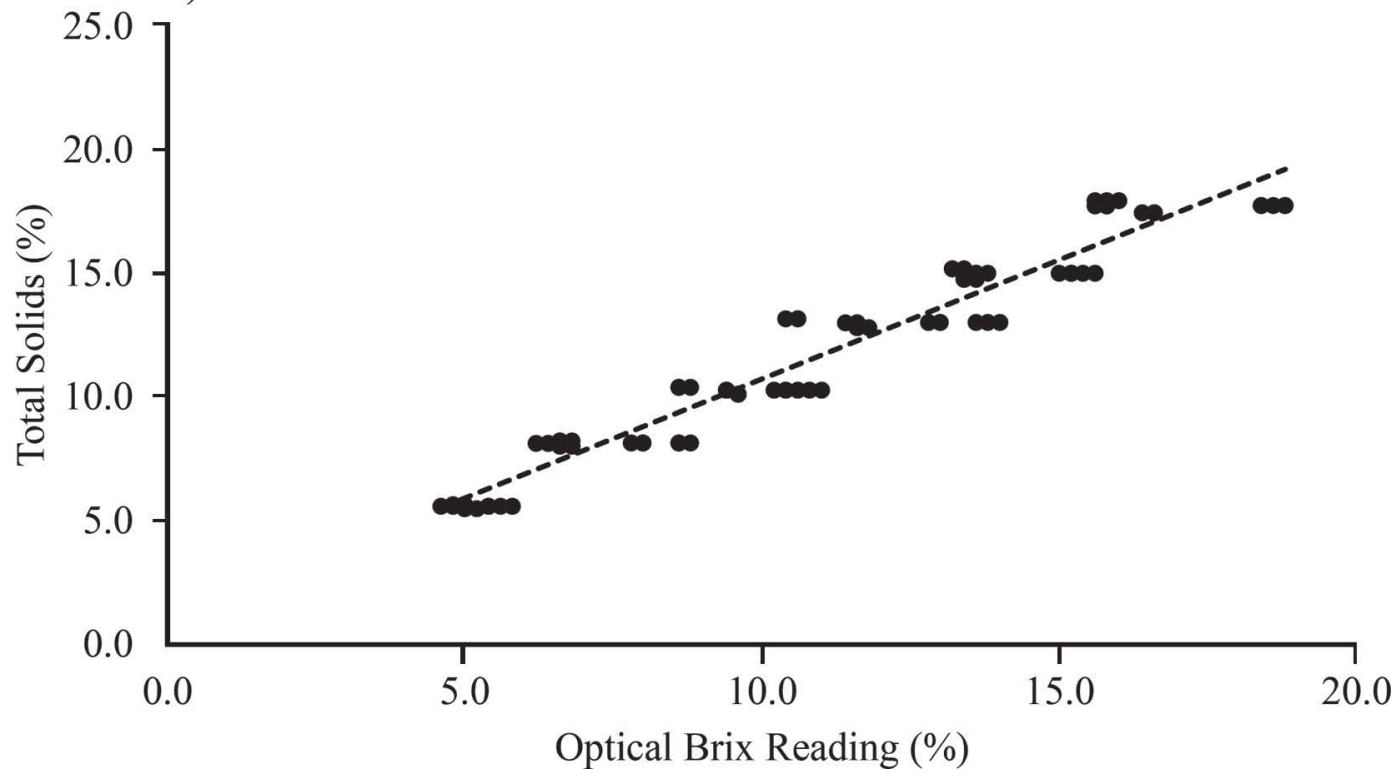

Figure 1. (a) Total solids of milk replacer solutions (\%) compared with Brix readings (\%) determined by digital refractometer $(\mathrm{n}=90 ; \mathrm{y}=$ $\left.0.96 \mathrm{x}+1.47 ; \mathrm{R}^{2}=0.95\right)$ and (b) TS of milk replacer solutions (\%) compared with Brix readings (\%) determined by optical refractometer $(\mathrm{n}=$ $\left.90 ; \mathrm{y}=0.96 \mathrm{x}+1.08 ; \mathrm{R}^{2}=0.94\right)$. 


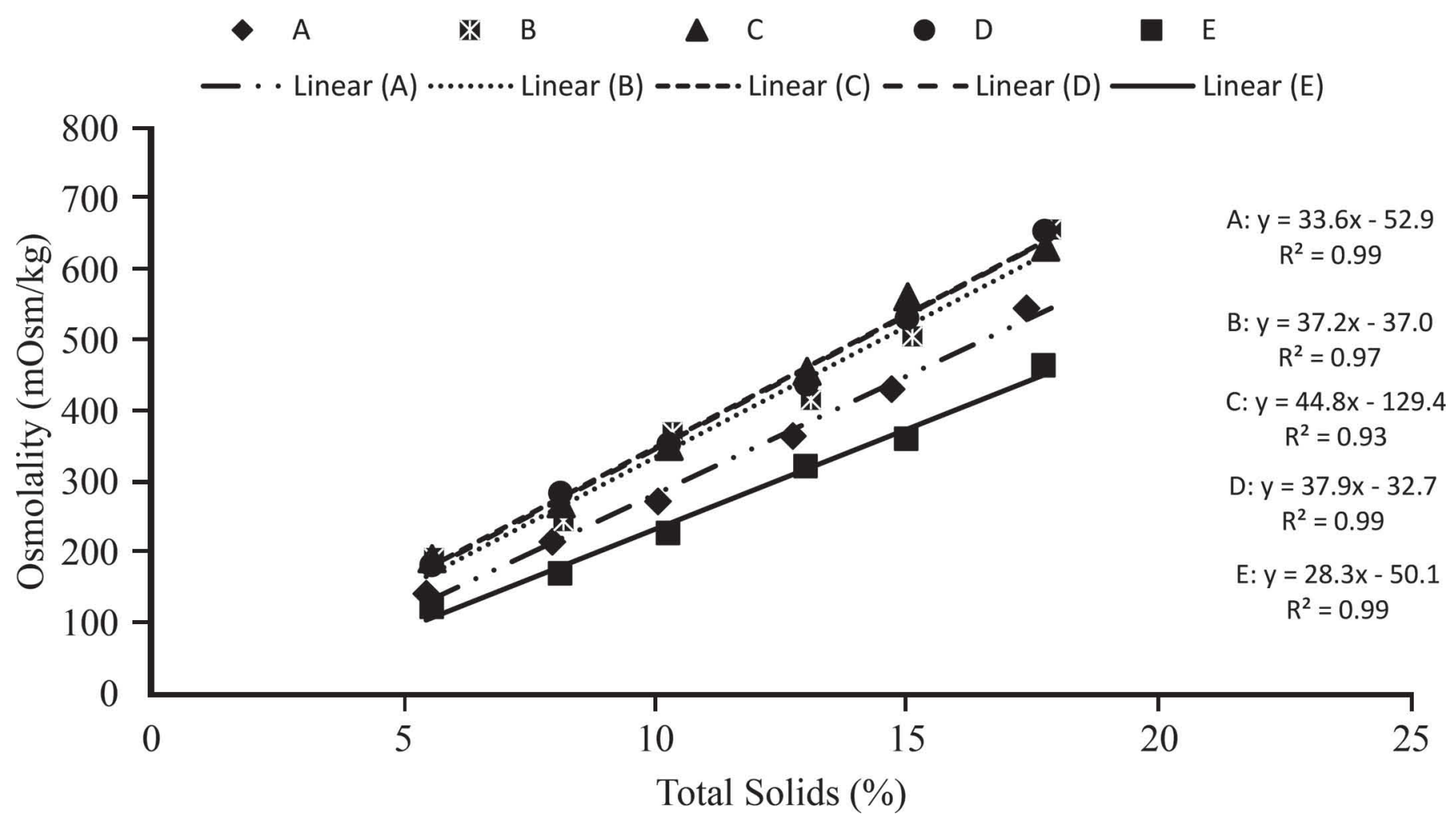

Figure 2. Osmolality (mOsm/kg; as measured by the Advanced Model 3320 Micro-Osmometer, Advanced Instruments Inc., Norwood, MA) of 5 different sets of milk replacer solutions (run in triplicates) at different concentrations (milk replacer A $=28 \% \mathrm{CP}, 25 \%$ fat; $\mathrm{B}=22 \% \mathrm{CP}$ $20 \%$ fat; $\mathrm{C}=22 \% \mathrm{CP}, 20 \%$ fat; $\mathrm{D}=22 \% \mathrm{CP}, 20 \%$ fat with mannan oligosaccharide; $\mathrm{E}=28 \% \mathrm{CP}, 25 \%$ fat) compared with TS.

effectively measured in a laboratory setting but might be prudent to evaluate when the milk replacer is being concentrated or new additives are used.

\section{ACKNOWLEDGMENTS}

The authors thank the dairy farmers and veterinarians for suggesting this research and the farmers for donation of the milk replacer powders. In addition, the authors thank Lindsay Tippett, Sandy Poisson, and Stephanie Wright (all from the Department of Veterinary Clinical Sciences, Washington State University) for technical support.

\section{REFERENCES}

Bach, A., M. Terré, and A. Pinto. 2013. Performance and health responses of dairy calves offered different milk replacer allowances. J. Dairy Sci. 96:7790-7797.

Bielmann, V., J. Gillan, N. R. Perkins, A. L. Skidmore, S. Godden, and K. E. Leslie. 2010. An evaluation of Brix refractometry instruments for measurement of colostrum quality in dairy cattle. J. Dairy Sci. 93:3713-3721.

Büttel, B., M. Fuchs, and B. Holz. 2008. Freezing point osmometry of milk to determine the additional water content-An issue in general quality control and German food regulation. Chem. Cent. J. 2:6. http://dx.doi.org/10.1186/1752-153X-2-6.
Constable, P. D., A. F. Ahmed, and N. A. Misk. 2005. Effect of suckling cow's milk or milk replacer on abomasal luminal $\mathrm{pH}$ in dairy calves. J. Vet. Intern. Med. 19:97-102.

Davis, C., and J. Drackley. 1998. Liquid feeding programs. Pages 259-282 in The Development, Nutrition, and Management of the Young Calf. Iowa State University Press, Ames.

Davis Rincker, L. E., M. J. VandeHaar, C. A. Wolf, J. S. Liesman, L. T. Chapin, and M. S. Weber Nielsen. 2011. Effect of intensified feeding of heifer calves on growth, pubertal age, calving age, milk yield, and economics. J. Dairy Sci. 94:3554-3567.

Deelen, S. M., T. L. Ollivett, D. M. Haines, and K. E. Leslie. 2014. Evaluation of a Brix refractometer to estimate serum immunoglobulin G concentration in neonatal dairy calves. J. Dairy Sci. 97:3838-3844.

Drackley, J. K. 2008. Calf nutrition from birth to breeding. Vet. Clin. North Am. Food Anim. Pract. 24:55-86.

Foster, D. M., and G. W. Smith. 2009. Pathophysiology of diarrhea in calves. Vet. Clin. North Am. Food Anim. Pract. 25:13-36.

Gelsinger, S., and J. Heinrichs. 2014. Precision is key to consistency in calf feeding. PennState Extension. Accessed Mar. 30, 2016. http:// extension.psu.edu/animals/dairy/news/2014/precision-is-key-toconsistency-in-calf-feeding.

Hill, T. M., H. G. Bateman II, J. M. Aldrich, and R. L. Schlotterbeck. 2009. Effect of consistency of nutrient intake from milk and milk replacer on dairy calf performance. Prof. Anim. Sci. 25:85-92.

Jenny, B. F., H. J. Van Dijk, and L. W. Grimes. 1982. Performance of calves fed milk replacer once daily at various fluid intakes and dry matter concentrations. J. Dairy Sci. 65:2345-2350.

Jodal, M., and O. Lundgren. 1986. Countercurrent mechanisms in the mammalian gastrointestinal tract. Gastroenterology 91:225-241.

Kertz, A. F., and J. R. Loften. 2013. Review: A historical perspective of specific milk-replacer feeding programs in the United States 
and effects on eventual performance of Holstein dairy calves. Prof. Anim. Sci. 29:321-332.

Khan, M. A., D. M. Weary, and M. A. G. von Keyserlingk. 2011. Invited review: Effects of milk ration on solid feed intake, weaning, and performance in dairy heifers. J. Dairy Sci. 94:1071-1081.

Marshall, T. S. 2009. Abomasal ulceration and tympany of calves. Vet. Clin. North Am. Food Anim. Pract. 25:209-220.

Moore, D. A., J. Taylor, M. L. Hartman, and W. M. Sischo. 2009. Quality assessments of waste milk at a calf ranch. J. Dairy Sci. 92:3503-3509.

Nouri, M., and P. D. Constable. 2006. Comparison of two oral electrolyte solutions and route of administration on the abomasal emptying rate of Holstein-Friesen calves. J. Vet. Intern. Med. 20:620-626.

Ollivett, T. L., and S. M. McGuirk. 2013. Salt poisoning as a cause of morbidity and mortality in neonatal dairy calves. J. Vet. Intern. Med. 27:592-595.
Quigley, J. D., T. A. Wolfe, and T. H. Elsasser. 2006. Effects of additional milk replacer feeding on calf health, growth, and selected blood metabolites in calves. J. Dairy Sci. 89:207-216.

Smith, G. W., and J. Berchtold. 2014. Fluid therapy in calves. Vet. Clin. North Am. Food Anim. Pract. 30:409-427.

Soberon, F., E. Raffrenato, R. W. Everett, and M. E. Van Amburgh. 2012. Preweaning milk replacer intake and effects on long-term productivity of dairy calves. J. Dairy Sci. 95:783-793.

USDA. 2012. Dairy Heifer Raiser, 2011. \#613.1012. USDA, Animal and Plant Health Inspection Service, Veterinary Service, Center for Epidemiology and Animal Health, National Animal Health Monitoring System (NAHMS), Fort Collins, CO.

Walker, P. G., P. D. Constable, D. E. Morin, J. K. Drackley, J. H. Foreman, and J. C. Thurmon. 1998. A reliable, practical, and economical protocol for inducing diarrhea and severe dehydration in the neonatal calf. Can. J. Vet. Res. 62:205-213. 